\title{
A MNEMÔNICA-NARRATIVA EM MÍDIAS DIGITAIS: o caso de Batatuba, uma vila operária
}

\author{
Sônia Barreto de Novaes ${ }^{1}$
}

Resumo: A presentidade da memória requer o agenciamento de dispositivos, atores e conteúdo, articulados dentro de uma perspectiva ecológica, onde a complexidade permite-nos compreender o Ser a partir de um processo mnemônico-narrativo. Em tal perspectiva o uso da forma (habitar) está a indicar a presença da sociabilidade e nesta as possibilidades, as negociações, as responsabilidades e as reapresentações, estas são camadas que verificamos no caso de Batatuba - uma vila operária no interior do Estado de São Paulo. Saímos, assim, de uma determinada condição histórica (heideggeriana) para uma consciência histórica (ricoeuriana). Então, também transitamos de uma condição midiática para uma consciência que, dentre outros modos de estar, está no ato midiático.

\begin{abstract}
The presence of memory requires the agency of devices, actors and content, articulated within an ecological perspective, where complexity allows us to understand the Being from a mnemonic-narrative process. In this perspective the use of form (habit) is indicating the presence of sociability and in this the possibilities, negotiations, responsibilities and restatements, these are layers that we verified in the case of Batatuba - a working village in the interior of the State of São Paulo. We thus leave a certain historical (Heideggerian) condition for a historical consciousness (Ricoeurian). So we also move from a mediatic condition to a consciousness that, among other ways of being, is in the mediatic act.
\end{abstract}

\section{A possibilidade, a negociação, a responsabilidade da reapresentação de Lugares de}

\section{Memória}

Ouço a ruína de todo espaço, de vidro quebrado e de paredes que caem, e o tempo, uma lívida flama final. James Joyce

Uma dimensão ecológica é uma dimensão agenciada inteligentemente que expressa um ser que é somente enquanto ser da presença (Dasein) ${ }^{2}$, isto é, um ser em:

[...] em relação com céu e terra, divinos e mortais, e que é somente sendo, ou seja, como possibilidade e ultrapassagem, ajuda a pensar a ação net-ativista como um dasein digital, expressão de uma ecologia que reúne, em forma similar à quadratura, indivíduo, dispositivos de conectividade, circuitos informativos e territorialidades. Uma condição habitativa. [...] (DI FELICE, 2013, p. 67).

\footnotetext{
${ }^{1}$ Doutora em Meios e Processos Audiovisuais; Mestre em Ciência da Informação e Bacharel em Biblioteconomia e Documentação pela Escola de Comunicações e Artes da Universidade de São Paulo. Experiência na área de mediação da informação e da cultura. Atualmente está como pesquisadora no grupo "Cidade do Conhecimento" da CTR/ECA/USP e no GENN - Grupo de Estudos sobre Novas Narrativas CRP/ECA/USP.

${ }^{2}$ Presença $=$ Dasein "[...] A palavra Dasein passa a ser usada na língua filosófica alemã no século XVIII como tradução da palavra latina prasentia. [...]" (SCHUBACK in HEIDEGGER, 2009, p. 561) Linares usa o termo "estar-en-el-mundo" como tradução para Dasein. (LINARES, 2008, p. 57).
} 
Esta "quadratatura" tangencia nosso posicionamento teórico e prático que está representado na tríade conceitual interativa e operacional que envolve:

a) O lugar de memória (Novaes, 2014) que através de uma dada materialidade compõe junto com esta a dimensão simbólica que garante a cristalização das lembranças e sua transmissão e; a dimensão funcional que faz a conexão aos ritos fundadores. Todavia os elementos que colocam estas dimensões do lugar de memória em movimento são: a vontade/desejo; decisão/escolha; busca/curiosidade.

b) A mídia digital (Paker, 2002) - que se distingue das demais em ao menos cinco pontos: 1) quanto à integração é hibrida; 2) é interativa; 3) a escrita não-linear e os esquemas de "linkagens" conferem-lhe hipermídia; 4) presenta características imersivas que podem incluir formas arquitetônicas ou geográficas de navegação e; 5) apresenta uma narratividade cujos desdobramentos se realizam por meio da participação ativa do grupo.

c) A narrativa transversal (Novaes, 2014) - constituída por narrativas singulares cujos elementos conectores evidenciam pontos comuns nas representações da memória. No caso de usar uma imagem para evocar uma lembrança, traz à tona, além da visibilidade icônica, a sua potência discursiva.

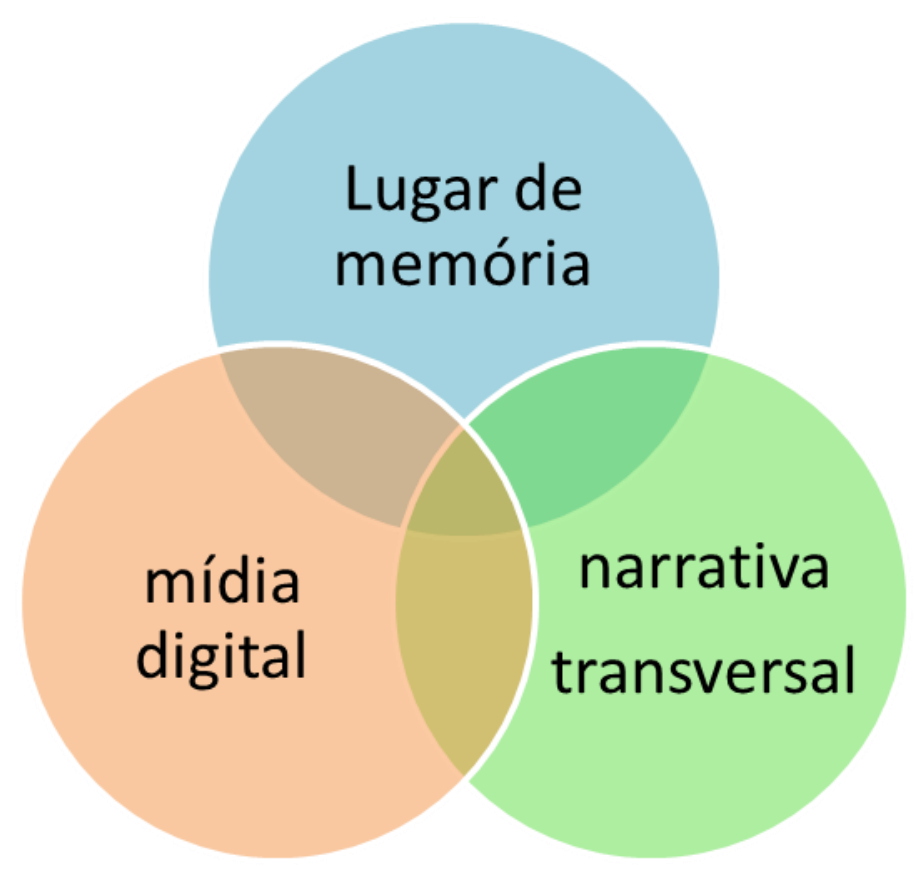


A figura acima representa o processo que relaciona as ações mnemônico-narrativas a um meio operacional, as mídias digitais. Este processo permite ressurgir o lugar de memória, que de alguma maneira estava lá, mas precisava vir à tona. Assim, o motor de toda essa operacionalidade é o ser, o qual, em sua temporalidade, comporta modos de ser e estar que envolvem ações, atributos, acontecimentos, competências e valores. As ações do ser estão sempre inacabadas porque vão confluir em outras ações, dir-se-á que ganham vidas, outras dimensões nem sempre previstas e, cabe-nos ressaltar aqui àquelas que percebemos diretamente relacionadas às questões éticas que perfazem o protagonismo - o poder-fazer. Sejam elas: as possibilidades, as negociações, as responsabilidades e as reapresentações.

A figura abaixo representa as aberturas que se dão enquanto narrativas permitem lembranças virem das memórias em movimentos que se estendem ao passado e ao futuro. Trata-se, portanto, de aberturas desde a base e em cada camada que se desenha a partir de uma possibilidade até a reapresentação da mnemônica-narrativa, mas não se encerra aí. São processos que vão se intercalando, nos quais uma camada não exclui a outra, ao contrário, há intensa comunicação entre elas.

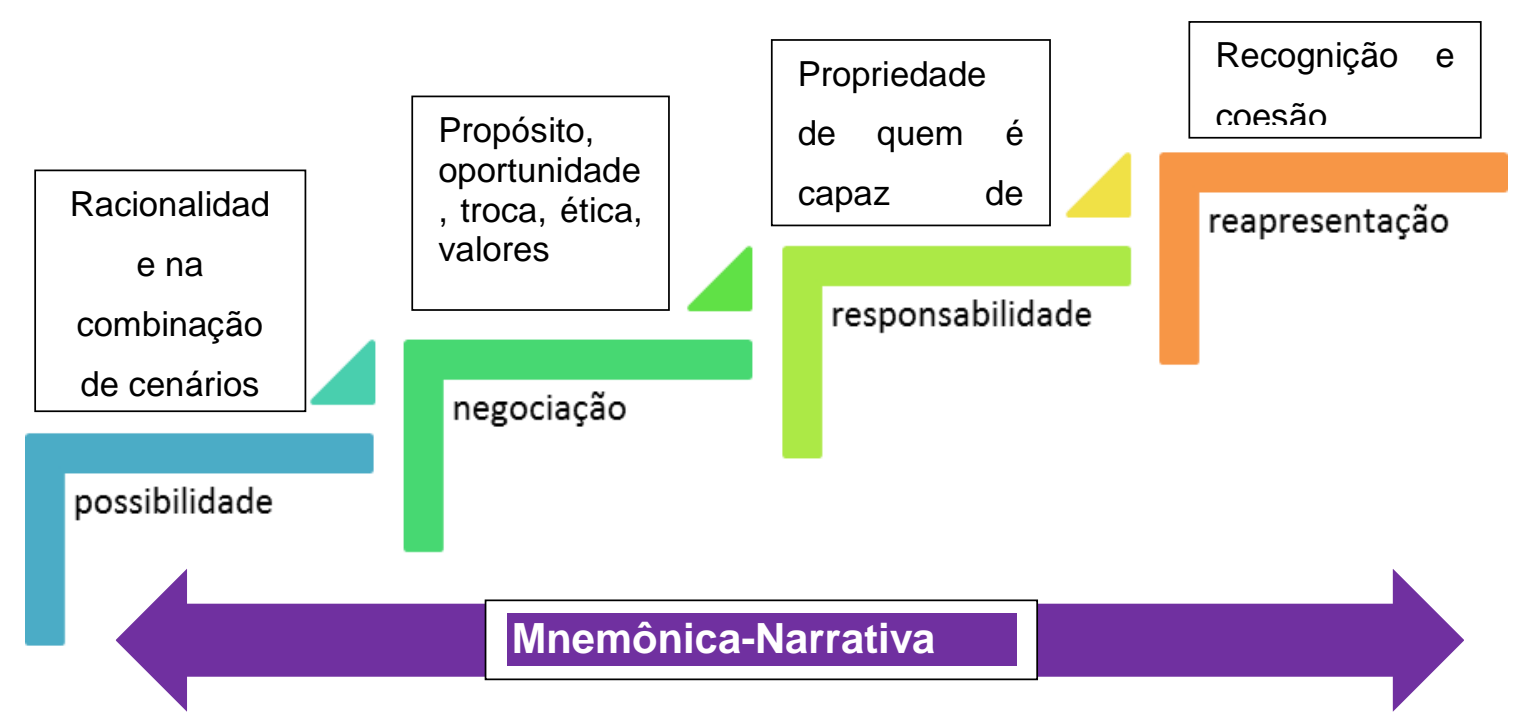

Quadro do processo de abertura da possibilidade à reapresentação ${ }^{3}$

\footnotetext{
${ }^{33}$ Quadro apresentado na Tese de doutoramento em "Meios e Processos Audiovisuais" (NOVAES, 2014, p.
} 158). 
Queremos dizer com este quadro que é numa distentio que se conduz em virtude de uma intentio que devido ao triplo presente (Santo Agostinho) se move para o futuro e para o passado, é aí que as possibilidades se abrem às negociações, estas por sua vez requerem responsabilidades que têm a ver com o ser capaz de cuidar num mundo que solicita cada vez mais atitudes, assim, quando feito algo, o querer compartilha-lo, isso é próprio do ser social e, toda obra já nasce, de certa maneira, com essa reinvindicação - de ser vista, apropriada, comunicada, significada, em uma palavra - reapresentada.

No entanto quanto mais elementos são tirados da expectativa, quanto mais a ação avança, mais se abrevia a expectativa e mais se alonga a memória, "até que a expectativa inteira se consuma, quando a ação inteira acabou e passou para a memória"4. A narrativa tem esta característica ímpar de envolver em si os três tempos simultaneamente: o passado, quando busca na memória; o presente, quando gera o campo de atenção e; o futuro, expectativas alimentadas por trends - tendências que preenchem a narrativa por vezes "fraturadas".

Recorremos, em termos de mídias digitais à rede social Facebook, como um recurso aplicado à atenção e também como um meio evocativo. As reapresentações que aí ocorrem, tais como a publicação de comentários, depoimentos e fotos que retratam épocas e os costumes de seus lugares. Todas essas reapresentações são maneiras de se apropriar dos espaços. O uso da rede é evocativo, e também um chamado para discussões fundamentais sobre assuntos diversos, tendo como indicador, no entanto, a ordem do dia a dia em diferentes escalas, níveis de abrangência. Através de fotografias, por exemplo, postada nas redes, sujeitos fazem projeções - os "factos fenomenológicos da visão", e impõe assim a visão como modo de relacionamento com um mundo ao qual já não sentimos pertencer, mas ao mesmo tempo em que exprime o ceticismo, contém também as condições da possibilidade da sua superação. Assim, quando há interesse, a inovação bebe do tradicional, em todo caso é visível o poder das narrativas em intervir no sistema.

A questão de trazer à tona o mundo fugidio por meio de mídias digitais, foi um dos pontos centrais no entendimento do lugar e dos processos aí envolvidos e que também influenciam o modo de ser. Vale ressaltar que a própria escolha do lugar - Batatuba - que é um bairro/distrito de Piracaia (86km da capital paulista), que é vila operária e foi construída

\footnotetext{
${ }^{4}$ SANTO AGOSTINHO apud RICOEUR, 2010, v.1, p. 37.
} 
para ser sede mundial das indústrias de calçados Bata no século passado e agora (há 37 anos) uma "Massa Falida"; passando pelas redes Facebook ${ }^{5}$ e, em relação aos vídeos (playlist no Youtube $^{6}$ ) - o modo que escolhemos, dentre tantas outras possibilidades, para reapresentar o lugar, a configuração do mapa colaborativo ${ }^{7}$, a maneira de postar e se colocar em rede. A todo o momento tivemos os imperativos das camadas apresentadas no quadro acima e vamos definir agora, um pouco mais:

a) Sobre as possibilidades - a pesquisa sobre como as mídias digitais interferem ou provocam uma determinada localidade poderia ter sido em qualquer local, no entanto, por suas configurações o bairro de Batatuba se apresentou como um cenário favorável e curioso para a sistematização de um arranjo digital e, por que não in locus? Assim, elencamos elementos, harmonizamos e racionalizamos e cuidamos para que tal arranjo comportasse uma poética que conduzisse quem dele se aproximasse a outras possibilidades, daí escolhas e negociações.

b) Negociações - ainda que seja simbólico, este momento requer sempre propósitos/justificativas. "Por que esse interesse todo pela história de Batatuba?" A resposta também determina o valor de troca, de cambiar informações e mesmo decisões. Trata-se de um propósito com valores e ética permeando-o, assim as responsabilidades se avizinham com certas competências.

c) Responsabilidades - "negócio" aberto, que vou fazer com isso? Chega o momento de cuidar, de conferir destinos. Enquanto cuidamos o objeto se desenvolve, mostra a vida que carrega em si. Se revela em prismas e confirma que: "Só quem possui responsabilidade é capaz de cuidar." No caso de Batatuba, a questão da responsabilidade envolveu a responsividade dialógica por conta da própria natureza do campo, já mencionado acima.

d) Reapresentações - Fomos presenteados com as representações e presenteamos com as reapresentações. Estamos diante de informações que podem conotar outras dinâmicas à comunidade. É a ocasião de compartilhar, de colocar no mundo suas

\footnotetext{
${ }^{5}$ Batatuba e seus lugares de memória. Disponível em 〈https://www.facebook.com/groups/540336372680621/>. Acesso em: 23 abr 2018.

${ }^{6}$ Revelando Batatuba. Disponível em < https://www.youtube.com/playlist?list=PLPwtCvbkaHdNIVwWCS8PhwH1b4qvm_QT>. Acesso em: 23 abr 2018.

${ }^{7}$ Batatuba: Lugares de memória. Disponível em: <https://drive.google.com/open?id=1VOCAguL7HEFPeiO4t6sAtCC8a9w\&usp=sharing>. Acesso em: 23 abr 2018.
} 
grandezas e fazer outros saberem e provocarem-no (Ge-stell) a, também, abrir a outras possibilidades. O Grupo no facebook cresceu surpreendentemente - e por conta das interações Batatuba hoje está em vias de firmar parcerias ${ }^{8}$ com outras cidades também construídas por Jan Antonin Bata.

Ainda em termos de reapresentações vale trazer a referência de Bill Nichols (2005) quando nos fala sobre as questões éticas para o cinema documentário, embora não tenha sido o caso, houve durante a pesquisa a construção documental audiovisual, e neste sentido podemos considerar o que este autor aponta sobre o vínculo do documentário e o mundo histórico, do engajamento pela representação: a) a representação reconhecível do mundo; b) a significação ou representação de interesses dos outros; c) a dependência de um determinado ponto de vista. O "eu falo deles para vocês" - implica um "eu" - a voz, o narrador, o cineasta; “deles" - $3^{\mathrm{a}}$ pessoa - de quem ou do que se fala, separação/distanciamento entre quem fala do eu para vocês.

Se falarei o que vou falar, preciso ter alguma garantia de que minhas palavras estarão guardadas conforme disse, igualmente é a imagem que vai junto com a fala. Já no momento da representação, o narrador precisa consentir com os termos que ali se pautam.

Aqui temos a questão da responsabilidade para com o outro imbricada, o que reforça o nosso dizer que as camadas da mnemônica-narrativa dialogam. A responsabilidade pauta a ética na negociação. Vale, então, trazer aqui a abordagem ética para a tecnologia de Hans Jonas, filósofo estudado por Jorge Linares. Segundo ele são quatro princípios éticos para o mundo tecnológico 9: 1) responsabilidade; 2) autonomia; 3) justiça e; 4) precaução. Tais princípios obrigam a comunidade mundial a travar um debate público permanente em busca de conhecimentos, deliberações e tomadas de decisões aceitáveis para a maioria. Assim, são preconizados os princípios éticos para o mundo tecnológico e para a sociedade global democrática.

O poder tecnológico expande a responsabilidade, dentro de um imperativo moral (LINARES, 2008), na qual o dever ético com os contemporâneos e com as gerações futuras fica a cargo do coletivo, porquanto se trata da "biosfera e da condição humana".

\footnotetext{
${ }^{8}$ Em 18 de março foi celebrada a parceria com o Centro de Memória “Jindrich Trachta" de Batayporã (Cidade também fundada pelo industrial calçadista tcheco - Jan Antonin Bata) - e agora somos Núcleo Complexo de Batatuba.

${ }^{9}$ Princípios baseados na bioética de Tristram Engelhardt - Linares, 2008, p. 441-494.
} 
[...] El ser humano es autoconsciente de su proprio ser mediante una representación simbólica, mediante una imagen de su esencia. Pero la imagen misma se convierte en el objeto de conocimiento de su proprio ser. [...] la idea del hombre expresa el carácter proteico de lo humano; es decir, la capacidad de transformar su proprio ser en la historia." (LINARES, 2008, p. 303 - nota de rodapé).

Podemos perceber, nos estudos sobre outros filósofos de Linares que as camadas aqui por nós descritas, estão intimamente relacionadas. Como ele salienta, o homem "[...] no necesita transmutarse porque él es siempre ser de la posibilidad [...]” (LINARES, 2008, p. 316) e é por ser um ser de possiblidades que o homem vale, e sua responsabilidade está “"[...] en función del poder y de la acción intencional. Su base ontológica es la libertad inherente al ser humano [...] La responsabilidad se realiza como un responder ante alguien por las consecuencias de las acciones, aunque nadie pida razones y cuentas. [...]” (idem, p. 326)

Sem a responsabilidade o valor das coisas não se manifesta e não pode ser reconhecido e, essa consciência responsável é consequência do caráter simbólico do homem, da sua independência e de seu sentido moral. Ou seja, sem a responsabilidade à negociação cambia do nulo ao negativo, em termos de valor e, é evidente que isso reflete na reapresentação. Vale ressaltar ainda que, significar está, no caso da narrativa, para um sentido que é pessoal e que pode ser público. (NOVAES, 2014, p. 161).

Mais uma vez a negociação de lembranças alimenta a cumplicidade gerada entre duas ou mais pessoas dispostas a ouvir e a contar. Dentro do espaço das experiências cambiadas habita o horizonte das expectativas. Ecléa Bosi, em "Memória e sociedade", questiona: "Por que decaiu a arte de contar histórias?" Ela mesma responde: "talvez porque tenha caído a arte de trocar experiências.” (BOSI, 1994, p. 28) Também Candau nos lembra que o narrador:

[...] parece colocar em ordem e tornar coerente os acontecimentos de sua vida que julga significativos no momento mesmo da narrativa: restituições, ajustes, invenções, modificações, simplificações, sublimações, esquematizações, esquecimentos, censuras, resistências, não ditos, recusas, vida sonhada, ancoragens, interpretações e reinterpretações constituem a trama desse ato de memória que é sempre uma excelente ilustração das estratégias identitárias que operam toda narrativa. (CANDAU, 2012, p. 71)

Temos então um passado que "funciona" como aberturas possíveis no presente. Este passado "útil", ou a "memória feliz" no dizer de Ecléa Bosi - aquela que lembra, serve para transmitir criar estratégias identitárias (Candau, 2012). Quase sempre conflitiva a memória trabalha entre os lados sombrios e os luminosos. Aquilo que deve ser lembrado e aquilo que deve ser esquecido e o cuidado com o engajamento responsável. Àquele que ouve e registra cabe o discernimento do que deve ou não ser revelado ao público. É assim que o trabalho da 
memória e sobre a memória busca criar um mundo relativamente estável e verossímil e até previsível cujos desejos e projetos ganham sentidos. Narrar é estabelecer conexões entre variáveis valorativas do todo com a parte, sejam elas temporais e espaciais. A narrativa oscila, então, entre a ficção e a realidade, operando entre a macro e a micro-história:

[...] Na medida em que uma presunção de submissão dos agentes sociais parece solidária com uma escolha macro-histórica de escala, a escolha micro-hsitória induz uma expectativa inversa, a de estratégias aleatórias, nas quais são valorizados conflitos e negociações, sob o signo de incerteza. [...]”' (RICOEUR, 2007, p. 230)

Estendendo o olhar e indagando a respeito da micro-história, no caso de Batatuba, temos um emaranhado de complexidades onde vacilam mensagens ambíguas e que, em certos casos, se opõem, ou melhor, se manifestam em relação à circulação, à negociação e à apropriação. Essas mensagens estão para aquilo que Heidegger define como "falação" ocorrida dentro da cotidianidade, do impróprio e da medianidade, na qual a presença é tomada como algo "[...] que pode ser gerenciado e calculado. A "vida" é um "negócio", independentemente se ela cobre ou não os custos. [...]" (HEIDEGGER, 2009, p. 370) Este falar impróprio que pode comprometer o desenvolvimento narrativo. É certo que, a microhistória opera continuamente em uma única e mesma escala de uma comunidade, de um grupo de indivíduos e de famílias, "[...] é nesse nível que se desenrolam negociações, conflitos e que se descobre a situação de incerteza que tal história evidencia. [...]" (RICOEUR, 2007, p. 257).

\begin{abstract}
Nesse sentido, a micro-história não deixa de situar num percurso de mudança de escala que ela narrativiza enquanto se faz. A história, tal como contada pelos moradores de Batatuba nos surpreendeu com sua riqueza de detalhes, mas também trouxe a incerteza do "que será" que vai acontecer. É preciso ressaltar também que a maneira como cada qual narrou sua versão dos ocorridos, dotou estas pessoas da situação, quer dizer, elas se viram dentro de possibilidades e, portanto, diante das aberturas mnemônicas que a narrativa trazia. (NOVAES, 2014, p. 163)
\end{abstract}

Mesmo com toda a incerteza em relação ao futuro da "Massa Falida Sapaco", o que se verificou nas histórias contadas foi uma narrativa nostálgica colorida "dos bons tempos eram aqueles" e imaginativa de um horizonte a alcançar fincado em raízes comuns a partir de um destino compartilhado (reapresentação).

Neste sentido, a "sequência elementar" de Claude Bremond abordada por Ricoeur como sendo uma "reflexão crítica à obra de Propp" aponta para os "desfechos" narrativos: 


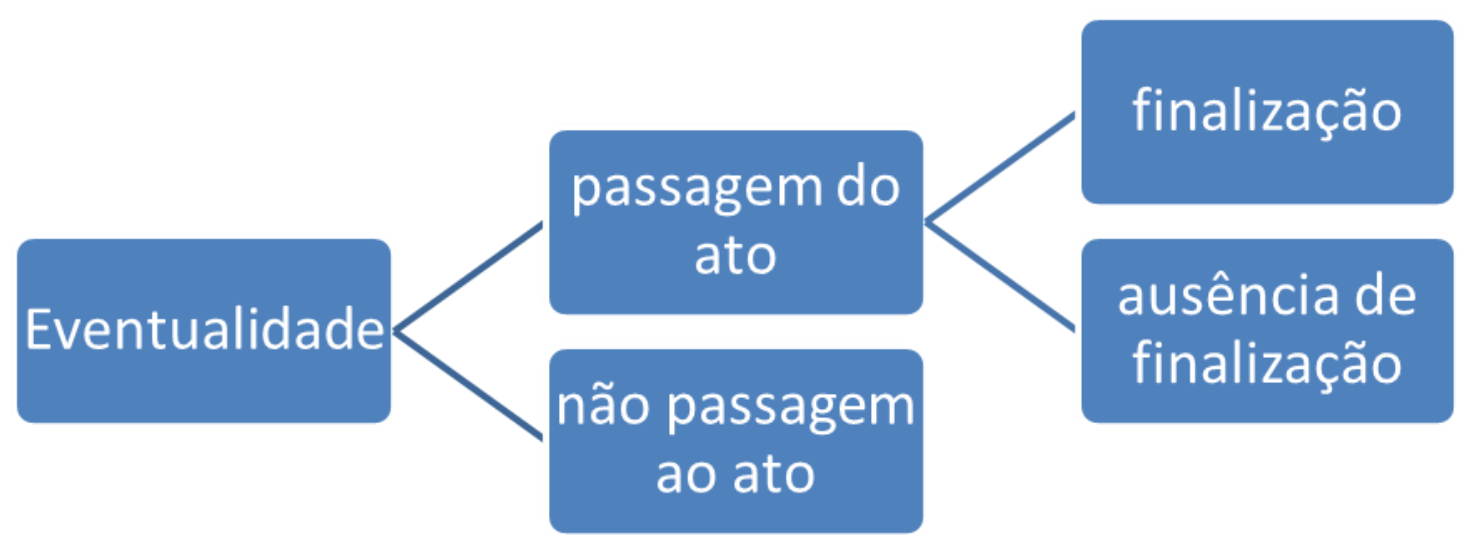

Interessa-nos neste enunciado as aberturas que uma dada "eventualidade" pode provocar, como afirma Paul Ricoeur: “[...] Podemos dizer sem nenhuma hesitação que essa sintaxe topológica das transferências é verdadeiro motor da narração 'enquanto processo criador de valores"” (RICOEUR, 2010, v. 2, p. 87, grifo nosso).

A ideia de uma ausência de finalização da eventualidade vai ao encontro da nãofinalizabilidade da dialogia bakhtiniana - termo diretamente relacionado à inovação, à 'surpreendência', ao genuinamente novo, à abertura e à potencialidade. (MORSON; EMERSON, 2008, p.55), daí voltamos novamente ao novo que se alimenta do tradicional... Da teoria bakhtiniana, ainda nos interessa a noção de responsividade, que é uma tradução da palavra russa "otvetsvennost" em que estão vinculados tanto a 'pergunta' quanto a 'resposta'. Bakhtin nos diz que a obrigação na responsividade "[...] é resgatar o outro do puro potencial; chegar a uma outra consciência faz o outro aglutinar-se e transforma o 'mero potencial' do outro num espaço aberto ao acontecimento vivo. [...]" (idem, p.93-94).

\footnotetext{
Ora, responder e questionar com responsabilidade e ética envolvem a presentidade, ou seja, estar de corpo inteiro, com todos os sentidos na situação/relação, em outras palavras na linguagem popular: "ser todo ouvido". Estes termos bakhtinianos nos remetem ao Dasein heideggeriano, o ser-aí e o cuidado diante do mundo, das possibilidades e das eventualidades que nos afetam cotidianamente. (NOVAES, 2014).
}

Por meio das narrativas podemos agenciar os elementos que garantem a organicidade de uma inteligência. $\mathrm{O}$ arranjo deve prever perspectivas valorativas, porque os fatos narrados 
nascem de pontos de vistas, de enquadramentos. As perspectivas podem ou não estarem embasadas em documentos oficiais, porque independente da prova está quem conta, quem narra e, este narrador está fundamentado nos valores que está transmitindo.

[...]. Tudo indica que estes valores axiológicos profundos representam mais que estereótipos culturais e ideologias. Os valores respectivos da vida e da morte são assumidos por todos os homens; o que é próprio a tal cultura, a tal escola de pensamento, a tal contador é aplicar esses valores-chave à figuras determinadas [...]" (RICOEUR, 2010, v. 2, p. 91)

Aplicar os valores-chave é ação de quem conta e com isso promove, direta ou indiretamente, o desenvolvimento do local onde está inserido. A apropriação e a negociação que cada qual faz com suas lembranças cooperam na construção da identidade individual e alimenta a coletiva, além de capacitar o sujeito nas investidas de uma vida comunitária de forma consciente, enraizada igualmente na identidade múltipla e nos processos que a memória evoca.

\section{Considerações finais}

Múltiplos acontecimentos perfazem as narrativas, principalmente aquelas autobiográficas, mas falar do outro é também falar um pouco de si. Nesses fenômenos aportam a trama "con-fiada", os arranjos mnemônicos, os mitos, os déficits mnésicos em virtude da idade ou de outros delírios da memória e dos sonhos e, são por estes fenômenos, dentre outros, que se rejeita estabelecer ou classificar em verdadeiro ou falso, mesmo aquelas narrativas que aparentemente manifestam pouca credibilidade. A verdade será sempre em razão a uma consideração, a uma concordância.

$\mathrm{O}$ que nos importou, e ainda importa (posto que o trabalho continua) na narrativa transversal de Batatuba foram aquelas particularidades encontradas no seio das narrativas singulares de pessoas que viveram ou tiveram algum tipo de envolvimento com as questões fábrica de calçados e com seu fundador Jan Antonin Bata. Diante desta concordância devemos dizer que nos servimos de uma topoanálise - estudo sistemático dos lugares da vida íntima (BACHELARD, 1978), a qual tem a marca da topofilia - esse "locus de reminiscências e o meio de se ganhar a vida" (TUAN, 1980, p. 107)

Assim, a temporalidade humana é marcada por seus meios e com a história da memória não poderia ser diferente. Ela obedece também às condições de seus meios de 
transmissão, que são os meios desenvolvidos pela humanidade. Passa-se da oralidade para a escrita e caminhamos até aportarmos nas tecnologias da informação e da comunicação. A representação do passado é, então a reapresentação - uma nova abordagem daquilo que já foi representado e também um encontro num outro agenciamento - seja ele, o das mídias digitais.

Se "narrar é equilibrar-se entre tempos" (NOVAES, 2014), neste ponto de equilíbrio reconstruímos lugares adentrando espaços e nos desvencilhamos de outros.

A princípio Batatuba se apresentou como um campo hostil às tecnologias, tendo em vista que sequer o celular funcionava. A questão era: "Como trabalhar com mídias digitais aqui?”; outra era: "Pior, não sinto nada por este lugar, ele não me diz respeito.” Então, estava eu naquele lugar, querendo descobrir o meu "leitmotiv", mas encontrei na Biblioteca o livro: "O mundo compreenderá: a história de Jan A. Bata: o Rei do sapato", com fortes indícios de ser uma autobiografia, mediante a leitura o início de um profundo envolvimento e um "enredar" que ainda permanece e promete frutos. Assim começamos a colher as narrativas poéticas, aquelas que se constroem e vão compor o arranjo a ser apresentado. Agora as narrativas da memória do que foi e fez Jan Antonín Bata se soma a outras narrativas de seus feitos em vários cantos do mundo. Por meios digitais, foi possível propagar a História desta Vila e alcançar parcerias que estão em outros continentes.

\section{Referências}

ARCHANJO, F. M. O mundo compreenderá: a história de Jan A. Bata - o Rei do sapato. Rio de Janeiro: Aurora, 195?

BACHELARD, G. A filosofia do não; O novo espírito científico; A poética do espaço. São Paulo: Abril Cultural, 1978.

BENJAMIN, W. Obras escolhidas: magia e técnica, arte e política. São Paulo: Basiliense, 1994.

BOSI, E. Memória e sociedade: lembranças de velhos. 15. ed. São Paulo: Companhia das letras, 1994.

CANDAU. J. Memória e identidade. São Paulo: Contexto, 2012.

DENZIN, Norman K. et al. O planejamento da pesquisa qualitativa: teorias e abordagens. 2. ed. Porto Alegre: Artmed, 2006. 
GARDE-HANSEN, J. MyMemories?: personal digital archive fever and Facebook. In: Save as: digital memory practices. Palgrave Macmillan, 2009.

GARDE-HANSEN, J. Media and Memory. Edinburgh University Press, 2011. (a review by Elena Caoduro).

HEIDEGGER, M. O caminho do campo. São Paulo: Livraria Duas Cidades, 1969. . Ser e tempo. 4. ed. São Paulo: Vozes, 2009.

LE GOFF, J. História e memória. 7. ed. rev. São Paulo: UNICAMP, 2013.

LINARES, J. E. Ética y mundo tecnológico. Ciudad del Mexico: UNAM, 2008.

MASSEY, D. Um sentido global do lugar. In. ARANTES, A. A. (org.) O espaço da diferença. São Paulo: Papirus, 1994. pp. 176-185.

MIÈGE, B. A sociedade tecida pela comunicação: técnicas da informação e da comunicação entre inovação e enraizamento social. São Paulo: Paulus, 2009.

MIELI, A. M. O audiovisual na era do youtube: pro-amadores e o mercado. In: Sessões do imaginário. ano xv, n. 25, p. 52-59 Disponível em:

< http://revistaseletronicas.pucrs.br/ojs/index.php/famecos/article/viewFile/9258/7133> Acesso em: 29 jun 2014.

MORSON, G. S.; EMERSON, C. Mikhail Bakhtin: criação de uma prosaística. São Paulo: EDUSP, 2008.

MUMFORD, Lewis. A cidade na história: suas origens, transformações e perspectivas. São Paulo: Martins Fontes, 1998.

NICHOLS, B. Introdução ao documentário. 3. ed. Campinas: Papirus, 2005.

NOVAES, S. B. de. Lugares de memória em mídias digitais: a narrativa transversal de Batatuba. Tese (doutorado)- em Meios e Processos Audiovisuais. Escola de Comunicações e Artes da Universidade de São Paulo. São Paulo, 2014. Disponível em: < http://www.teses.usp.br/teses/disponiveis/27/27161/tde-18052015-171247/pt-br.php>. Acesso em: 20 abr 2018.

PACKER , R.; JORDAN, K. Multimedia: from Wagner to virtual reality. New York: Norton \& Company, 2001.

RICOEUR, P. A memória, a história, o esquecimento. Campinas: Unicamp, 2007.

Tempo e narrativa. São Paulo: WMF; Martins Fontes, 2010. [03 volumes]

TUAN, Y. F. Topofolia: um estudo da percepção, atitudes e valores do meio ambiente. Rio de Janeiro: Difel, 1980. 